\title{
DEVELOPMENT OF AGRICULTURAL INSURANCE SYSTEM
}

\author{
Yuliia Aleskerova ${ }^{1}$
}

\begin{abstract}
The purpose of the work is to substantiate theoretical and methodological principles and practical recommendations for defining the main landmarks, priority directions and the dominant components of the development of the agricultural insurance system. Agricultural insurance is an effective instrument for its financial support and ensuring the continuity of expanded reproduction, which promotes stabilization of production, ensuring the financial stability of agricultural producers and, thus, generates conditions for achieving the desired standard of living, food security of the state and the welfare of the population. The objectives of the study are: to consider genesis of views on the essence and role of the agricultural insurance system; to analyze the current contour of the agricultural insurance system; to substantiate the priority directions of development of the system of agricultural insurance. Method. The methodological basis of the study is the general economic method of ascending from abstract to concrete, theoretical achievements of domestic and world financial science, conceptual provisions of modern insurance theories. The research is based on the use of a systemic approach to the consideration of financial phenomena, on the fundamental positions of economic theory, system theory, theory of finance, insurance management, etc. Results. The concept of the development of the agricultural insurance system and its main implementation vectors determine the purpose, defining tasks is a more specific form of decision-making, requiring the elaboration of certain strategic measures. In this case these are to outline the criteria for evaluating the purpose, to determine the high-quality and quantitative characteristics of these criteria. High-quality characteristics are understood as a landmark and quantitative as a task. Value/originality. Improved theoretical and methodological approaches to the definition of the essence and structure of the agricultural insurance mechanism have allowed to propose conceptual provisions for the harmonization of the mechanism of agricultural insurance, this will allow to take into account the inquiries, interests and financial opportunities of agricultural producers comprehensively in order to minimize adverse effects of agricultural risks depending on the intensity and level of their manifestation, on the basis of which a bunch of effective measures is developed, which allows to ensure the leveling of threats and the dynamism and flexibility of the system, which will facilitate the provision of insurance protection of agricultural produces and increase of export potential of agriculture.
\end{abstract}

Key words: insurance, agricultural insurance system, agricultural insurance mechanism, insurance risks, insurance products, innovative insurance tariff policy.

JEL Classification: O31, G22, J43, Q14

\section{Introduction}

Agriculture in Ukraine is considered one of the most risk industries since its functioning occurs in uncertain, unregulated and difficult natural and climatic conditions. The cardinal transformations in the agricultural insurance system conditioned by qualitatively new economic conditions, limited the obligatory methods of insurance protection, which were constantly used as state levers of influence on agriculture. However, the model of voluntary insurance with insurance subsidies remains acutely debatable. Currently the domestic agricultural insurance system is slowly developing at the expense of formal schemes, mainly in the extensive format, and is accompanied by a variety of financial, informational, analytical, organizational and institutional, and infrastructural issues. The problems of increasing the quality of insurance products, combining and harmonizing the interests of the participants in the agricultural insurance system, its structural modernization remain unresolved.

\footnotetext{
Corresponding author:

${ }^{1}$ Vinnytsia National Agrarian University, Ukraine.

E-mail: aleskerovaaleskerova@gmail.com

ORCID: https://orcid.org/0000-0003-3072-4854

ResearcherID: M-6099-2018
} 
In the present time, there is a contradictory process regarding finding the own model of development of the system of agricultural insurance. At the same time, they were closely intertwined with models that remained inherited from the administrative economy, as well as the latest progressive ones. In this section it is objectively necessary to consider the research of theoretical, methodological and practical aspects of the development on the scientific platform of strategies and a set of measures for the development of agricultural insurance system, taking into account the various instruments of state influence. The problems concerning the principles of construction and components of the system of agricultural insurance and insurance protection of agricultural producers in the context of ensuring its transparency, accessibility and information openness remain poorly covered. The revision of approaches to the selection of classification characteristics of insurance agricultural risks in view of expediency to clarify the pricing methodology of the insurance tariff is required. Few methods of research are non-traditional methods of agricultural insurance are proposed. The main guidelines and the dominant components of the development of strategies for the development of the agricultural insurance system need more consideration. Attention is paid to the harmonization of the mechanism of agricultural insurance.

\section{Economic crisis effects on consumer behavior}

The purpose of the work is to substantiate theoretical and methodological principles and practical recommendations for defining the main landmarks, priority directions and the dominant components of the development of the agricultural insurance system.

The object of research is a set of financial phenomena and processes concerning the formation, functioning and development of the agricultural insurance system.

The subject of the study is the development of the agricultural insurance system in the cut of theoretical, applied and methodological aspects.

The methodological basis of the study is the general economic method of ascending from abstract to concrete, theoretical achievements of domestic and world financial science, conceptual provisions of modern insurance theories. The research is based on the use of a systemic approach to the consideration of financial phenomena, on the fundamental positions of economic theory, system theory, theory of finance, insurance management, etc.

Consideration and definition of the vectors of progress and modernization of the agricultural insurance system is impossible without a detailed and in-depth scientific understanding of the genesis of views on the nature and place of insurance, the disassembly of basic relations, clarification of the conceptual apparatus since the inconsistency of key concepts leads to the inability to determine the offensive progress of this phenomenon.

\section{Differences in consumer spending behaviour among age groups}

Today, there is a need for the theory of insurance to solve new problems, which leads to the consideration, generalization and refinement of the scientific interpretation of insurance phenomena and processes that originated in domestic territories in the process of formation of a new economic model. The problem is compounded by the fact that the latest western scientific currents along with archaic socialist ones, should not be used mechanically in today's realities in Ukraine. Often, researchers are concerned with the practical orientation of insurance activity, considering its trends and do not immerse themselves in the essence of the conceptual apparatus, the content of insurance as an economic category. We agree with the well-founded statement of V. Bazulevych, who insists on the desirability of delineating the practical and essential contours of the study of insurance phenomena, because today "many theoretical, educational and practical published sources of insurance consider categories not as tools and steps of the process of knowledge of the phenomena inherent in insurance as a sphere of activity, but as the phenomena themselves". In the solution of theoretical and methodological questions of the theory of insurance, the secondary is the essential contour. It makes it possible to define the essence of insurance more clearly, promotes the discovery of new phenomena and trends, makes it possible to dismantle trends and patterns and develop new insights on the development of the insurance industry. Today, there are many scientific theories and trends concerning the consideration of the essence of insurance. The main ones are classical and neoclassical economic theories, the theory of mercantilism and marginalize, the theory of economic equilibrium, monetarism, neoliberalism, the teachings of J. Keynes, the theory of institutionalism and social market economy, the 
concept of neoclassical synthesis, the theory of risks, the theory of insurance protection, the theory of motivation, Maslow and Freud, the theory of the insurance fund, the ERG theory of C. Alderfer and others.

The conducted search assures that the isolation of property types of agricultural insurance is related to certain specific features: the specificity of the insurance objects, the types of insurance and the range of prevailing threats.

The object of agricultural insurance is the property interest in agricultural production, and the subject is the risk of loss of agricultural products, income of agricultural producers, their costs incurred in the production of agricultural products. Specific objects of agricultural insurance, as it is already noted, are agricultural plants and animals that have differences with other objects that are subject to property insurance, because they are wildlife. As K. Marx acknowledged, the dynamics of agricultural production are manifested as the dynamics of nature, which human tries to orient, and therefore natural phenomena act on him/her more force than on industrial production. Mainly, property insurance is carried out from the risk of fire (fire, explosion), in contrast, for agricultural insurance there are the main risks of accidents and diseases of livestock and poultry, and adverse natural disasters, and the risk of destruction of crops by diseases, pests, damage of crop production. We emphasize that agricultural risks are often outlined as anomalous risks (landslides, droughts, floods, showers). In terms of intensity, they can be catastrophic because they may spread over large territories in several areas. A fire can also cover a certain number of insured events, but the fire does not have a dominant effect. Only in the case of real estate insurance in agriculture it is dominance among insurance risks restored.

That is, in agricultural production, the process of reproduction is closely intertwined with the natural dynamics of the flow of living organisms (plants and animals), the development and the very existence of which are extremely dependent on natural events. This causes the devastating effects of adverse natural events on agriculture (severe frosts, floods, hail, droughts, showers). Yield fluctuations over the years are also due to the significant impact of adverse natural and climatic events (Table 1).

In addition, in the crop sector, the products produced have different costs over operating cycles. If the products are collected and brought to the pantry, then these products are subject to insurance as actual property, that is, in such a situation the main risks will be property risks. Depending on the stages or ripening of crops, dependence on natural factors will be dominant. In agricultural insurance, however, income from agricultural production is considered to be an object of insurance. If the yield decreases, the profits of the agricultural producers are reduced (Table 2), and the insurance payments are made upon the decrease, the crop failure. Thus, all the attributes of modern agricultural insurance are convinced that even with crop insurance, there is the risk of loss. The risk of loss should be attributed to economic or financial risks.

Specificity of agricultural insurance requires other methods of formation and exacting of insurance funds (basic, additional and preventive measures), calculation of probability of occurrence of an insurance event and determination of tariff rates of insurance.

It is important that the fixation of negative events is accompanied by the identification of preventive measures aimed at minimizing their adverse effects. Using the statistical methods of calculation, it is possible to calculate the mathematical expectation of the crop size in the section of crops. Such calculations will allow to determine the range of crops, the cultivation of which in the circumstances of a particular natural and climatic zone will be minimally risky. However, different crops do not respond identically to fluctuations in weather conditions, and the expediency of analyzing the

Table 1

Crop production in agricultural enterprises of Ukraine, thousand tons

\begin{tabular}{|l|c|c|c|c|c|c|c|}
\hline \multirow{2}{*}{ Product } & \multicolumn{9}{c|}{ Year } & Deviation \\
\cline { 2 - 8 } & 2005 & 2010 & 2011 & 2012 & 2013 & 2014 & max to min, \% \\
\hline Cereals & 28790 & 39271 & 56747 & 46216 & 63051 & 63859 & 319 \\
\hline Sugar beet & 12145 & 13749 & 18740 & 18439 & 10789 & 15734 & 268 \\
\hline Sunflower & 3709 & 6772 & 8671 & 8387 & 11051 & 10134 & 404 \\
\hline Potato & 19462 & 18705 & 24248 & 23250 & 22259 & 23693 & 165 \\
\hline Vegetables & 7295 & 8122 & 9833 & 10017 & 9873 & 9638 & 172 \\
\hline Fruits and berries & 1690 & 1747 & 1896 & 2009 & 2295 & 1999 & 158 \\
\hline
\end{tabular}


Table 2

Yield of basic crops, c / ha

\begin{tabular}{|c|c|c|c|c|c|c|c|c|c|}
\hline \multirow{2}{*}{ Product } & \multicolumn{8}{|c|}{ Year } & \multirow{2}{*}{$\begin{array}{c}\text { Deviation } \max \\
\text { to } \min , \%\end{array}$} \\
\hline & 1995 & 2000 & 2005 & 2010 & 2011 & 2012 & 2013 & 2014 & \\
\hline Cereals & 24.3 & 19.4 & 26.0 & 26.9 & 37.0 & 31.2 & 39.9 & 43.7 & 225 \\
\hline Sugar beet & 205 & 177 & 248 & 279 & 363 & 411 & 399 & 477 & 269 \\
\hline Sunflower & 14.2 & 12.2 & 12.8 & 15.0 & 18.4 & 16.5 & 21.7 & 19.4 & 178 \\
\hline Potato & 96 & 122 & 128 & 132 & 168 & 161 & 160 & 176 & 183 \\
\hline Vegetables & 120 & 112 & 157 & 174 & 195 & 199 & 200 & 208 & 185 \\
\hline Fruits and berries & 29.8 & 38.4 & 63.7 & 78.2 & 84.9 & 89.9 & 103.5 & 95.2 & 347 \\
\hline
\end{tabular}

degree of risk in the multiplicity of their effects on the generation of outputs is generated.

High risk of production of agriculturalproductsgives rise to high risk of activity of agricultural producers and low profitability (Table 3 ). The world experience assures that in the case of agricultural insurance, the state should be responsible for the losses caused to agricultural producers due to catastrophic risks and to provide at least partial compensation.

As we have already considered, a multilevel insurance reserves system is also created in Ukraine, which provides compensation for losses to agricultural producers in the event of large losses of yield from various natural disasters.

Agricultural insurance is more closely linked to the dynamics of formation of the insurance reserve of the insurer. Interestingly, throughout the state monopoly on agricultural insurance it was accompanied by the participation of a wide range of insurers (collective farms, state farms, rural population).

Agricultural producers can only be full-fledged insurers with strong agricultural production (thus, in terms of labor productivity, domestic agricultural production is ranked 35th in the world rankings).
Thus, we are convinced that agricultural insurance has significant features compared to other sectoral types of insurance, which adjusts the dynamics, mechanism, technology of agricultural insurance.

It is advisable to understand and adapt to this specificity in order to prevent the adoption of wrong decisions on agricultural insurance, which will contradict its essence and impede its development.

Agricultural insurance is a type of property insurance, but at the same time, it is considered as a specific insurance industry, which is complex, combining its various types. Agricultural insurance covers insurance for crops and perennial gardens, poultry, livestock, fur animals, bee families, cars, homes, structures, vehicles, gears, seeds, raw materials, finished goods, equipment, inventory, agricultural liability, so, it is performed in the comprehensive insurance format.

In economically developed countries, there are also different segments in agricultural insurance. In Canada, in particular, there are several insurance programs attached to the agricultural insurance group: crop insurance; animal insurance; income insurance for individual products; farmers' personal insurance; insurance of the producer's

Table 3

Profitability of certain types of agricultural production in Ukraine

\begin{tabular}{|c|c|c|c|c|c|c|c|c|c|}
\hline \multirow{2}{*}{ Product } & \multicolumn{8}{|c|}{ Year } & \multirow{2}{*}{$\begin{array}{l}\text { Deviation } \\
\text { max to min }\end{array}$} \\
\hline & 1995 & 2000 & 2005 & 2010 & 2011 & 2012 & 2013 & 2014 & \\
\hline Grain & 85.6 & 64.8 & 3.1 & 13.9 & 26.1 & 15.2 & 1.5 & 25.8 & 84.1 \\
\hline Sunflower seeds & 170.9 & 52.2 & 24.3 & 64.7 & 57.0 & 45.8 & 20.5 & 36.5 & 150.4 \\
\hline Sugar beet & 31.2 & 6.1 & 4.8 & 16.7 & 36.5 & 15.7 & 2.7 & 17.9 & 33.8 \\
\hline Open ground vegetables & 12.8 & -1.7 & 16.1 & 23.5 & 9.9 & -6.8 & 7.0 & 16.7 & 30.3 \\
\hline Potato & 34.3 & 14.0 & 17.8 & 62.1 & 17.7 & -21.5 & 23 & 9.2 & 83.6 \\
\hline Milk and dairy products & -23.2 & -6.0 & 12.2 & 17.9 & 18.5 & 2.3 & 13.6 & 11.0 & 41.7 \\
\hline \multicolumn{10}{|l|}{ Meat of: } \\
\hline cattle & -19.8 & -42.3 & -25.0 & -35.9 & -24.8 & 29.5 & -43.3 & -35.9 & 72.8 \\
\hline pigs & -16.7 & -44.3 & 14.9 & -7.8 & -3.7 & 2.0 & 0.2 & 5.6 & 49.9 \\
\hline sheep and goats & -31.9 & -46.4 & -32.1 & -29.5 & -39.6 & -40.0 & -42.8 & -52.2 & 22.7 \\
\hline birds & -18.4 & -33.2 & 24.9 & -4.4 & -16.8 & -7.2 & -10 & -15.4 & 58.1 \\
\hline Eggs & 36.5 & 10.6 & 23.5 & 18.6 & 38.8 & 52.6 & 47.6 & 58.8 & 48.2 \\
\hline
\end{tabular}


total income. An important class of agricultural insurance in the United States is crop insurance. At the same time, the agricultural insurance system covers the insurance of animals, property, life and income of farmers.

To be sure, agricultural insurance is a complex, broad-based concept that encompasses various areas of insurance: property, personal and liability. Therefore, it is logical that it is included in property, personal and liability insurance, which, at the same time, are considered varieties of insurance.

Despite a variety of theories and movements for the consideration of the nature of insurance, a common approach for the interpretation of the substantive content of insurance is still not developed. Consideration of the essence of insurance takes place in economic, financial, social, regulatory, sociological, mathematical, social, geographical, informational and other areas.

The most common is the characteristic of insurance as a combination of economic relations, the range of which includes the formation of a special insurance reserve and its exploitation (dismemberment and differentiation) to eliminate and cover various wastes, losses caused by negative events by means of insurance payments. Such an interpretation does not take into account that far from always the insurance indemnity is caused by the onset of the insurance event and has an adverse effect. Scientists K. Shelehov and B. Bigdach define the term "insurance" as: a set of economic relations; a branch of economic activity; a business direction; a tool to protect the property interests of participants. They propos a matrix of the term "insurance"

\section{Findings}

Based on the analysis of the potential of agricultural insurance and the provision of its relevant assets, it is appropriate to define the concept of development of the main guidelines and the dominant components of the development of agricultural insurance system development strategies. The concept of the development of the agricultural insurance system and its main implementation vectors determine the purpose. Defining tasks is a more specific form of decisionmaking, requiring the elaboration of certain strategic measures. In this case, it is necessary to outline the criteria for evaluating the purpose, to determine the high-quality and quantitative characteristics of these criteria. High-quality characteristics are understood as a landmark and quantitative as a task.

The benchmark for existing definitions in dictionaries is a pointer to the action vector. In practice, the benchmark is a specific strategic goal, for which the system is targeted and which is achieved due to strategies. The landmark and strategy are closely dialectically interconnected. That is, the benchmark is the outlined future prospect, a distant goal that must be achieved through defined strategies.

The strategy outlines a set of measures and forecasts for the achievement of certain benchmarks. They should take into account the potential of agricultural insurance. Please, note that for the implementation of some benchmarks, a strategy developed for the realization of others canot be used. Interestingly, there is a close relationship between the benchmarks and the strategy. In particular, such a characteristic as the segmentation of agricultural insurance may be determined as a benchmark but may be determined by a strategy.

\section{Conclusions}

The theoretical generalization and qualitatively new solution of the scientific problem concerning the substantiation of theoretical and methodological principles and practical recommendations concerning the determination of the main landmarks, priority directions and the dominant components of the development of the agricultural insurance system are presented in the paper. The results of the work make it possible to summarize the following conclusions and propositions of theoretical-conceptual, methodological content and scientific-practical direction for solving of the core problems.

It is substantiated that development of the system of agricultural insurance is important to consider in the cut of interests of the state, the insurer, the insured and their synthesis reflects the effectiveness of the whole system. The criteria and methodical approach to assessing the development of the agricultural insurance system is motivated, which helps identify existing or potential obstacles and problems of its functioning and disassemble the possibility of implementing the necessary preventive actions and preventive and corrective measures to minimize, eliminate or prevent them.

The directions of development of the system of agricultural insurance are defined: 
- it is advisable to streamline, systematize and harmonize the provisions of the various legal acts regulating insurance relations in agriculture;

- it is important to conduct a scientific and legal examination regarding the clarification of the interpretation of the provisions of the normative acts and the terminological use of the conceptual apparatus of agricultural insurance;

- it is expedient to radically change the attitude towards the institution of mutual insurance and promote the formation of these societies and their associations in agriculture;

- it is necessary to ensure the harmonization of the rights and obligations of all participants in agricultural insurance so that insurance companies do not refuse to insure agricultural commodity producers and the latter would wish to do so.

The development and introduction of new insurance products as an instrument of innovation in agricultural insurance and the cornerstones of insurance marketing, should cover all procedures: from advertising and insurance contracts to the search for investment mechanisms and progressive ways of corporate adjustment.

Today, agricultural insurance provides a redistribution of about $0.08 \%$ of GDP and only $20 \%$ of agricultural producers insure their risks. The exceptional characteristics of the modern system of agricultural insurance have been made impossible by the precise, unbiased diagnostics of its contour, the developed insurance products, the size of agricultural insurance, the potential capacity of the insurance agricultural market; contradiction of the formed regulatory legal field; the lack of a single informationstatistical array of agricultural insurance; insignificant level of demand for insurance products; mutual distrust of insurers; abolition of insurance subsidies for agricultural producers; deficit of profitable standardized insurance products.

It is revealed that insurers offer more than 50 insurance products covering almost 300 individual or corporate agricultural risks. Based on the study of insurance products of domestic insurers, identifying their advantages, opportunities and disadvantages, a multimodal comprehensive insurance program with a wide range of insurance products is offered. The proposed program allows to lower the insurance price, increases the level of insurance protection, promotes expansion of the agricultural insurance market. The ranking of external and internal factors influencing the mechanism of agricultural insurance has been identified, systematized and carried out.

Improved theoretical and methodological approaches to the definition of the essence and structure of the agricultural insurance mechanism have allowed to propose conceptual provisions for the harmonization of the mechanism of agricultural insurance. This will allow to comprehensively take into account the inquiries, interests and financial opportunities of agricultural producers in order to minimize adverse effects of agricultural risks depending on the intensity and level of their manifestation, on the basis of which a bunch of effective measuresis developed, which allows to ensure the leveling of threats and the dynamism and flexibility of the system, which will facilitate the provision of insurance protection of agricultural produces and increase of export potential of agriculture.

Using the above theoretical, methodological and practical developments will contribute to the growth and increase of the efficiency of the agricultural insurance system in Ukraine.

\section{References:}

Aleskerova, Yu., Mulyk, T., \& Fedoryshyna, L. (2018). Improving credit protection analysis methods Reports of main agricultural enterprises. Baltic Journal of Economic Studies, vol. 4, no. 2, pp. 1-7. doi: 10.30525/2256-0742/2018-4-2-1-7

Aleskerova, Yu., \& Fedoryshyna,L. (2018). Analysis of investment activities of enterprises of Ukraine.Economic system development trends: the experience of countries of Eastern Europe and prospects of Ukraine.

Aleskerova, Yu., Fedoryshyna, L., \& Koval, N. (2018). Features of loan security for the reproduction of fixed assets for agricultural purposes. Baltic Journal of Economic Studies, vol. 4, no. 4, pp. 1-5. doi: $10.30525 / 2256-0742 / 2018-4-4-1-5$

Aleskerova, Y., Kovalenko, L., \& Havryliuk, V. (2019). Innovative financial criteria for methodological approaches to the assessment of agrarian insurance. Baltic Journal of Economic Studies, vol. 5, no. 4, pp. 34-41. doi: 10.30525/2256-0742/2019-5-4-34-41

Rogach, S., Vdovenko, L., \& Polishchuk, O. (2019). Agriculture of Ukraine under the joint policy of the European Union. Baltic Journal of Economic Studies, vol. 5, no. 3, pp. 178-183. doi: 10.30525/22560742/2019-5-3-178-183 
Plakhtii, T., Fedoryshyna, L., \& Tomchuk, O. (2019). Socio-economic component of preferential taxation of individuals' incomes. Baltic Journal of Economic Studies, vol. 5, no. 2, pp. 171-175. doi: 10.30525/22560742/2019-5-2-171-175

Koval, N., Priamuhina, N., \& Zhmurko, I. (2020). Analyz economic - financial experience of the world countries in the system of pension insurance. Baltic Journal of Economic Studies, vol. 6, no 1, pp. 1-7. doi: $10.30525 / 2256-0742 / 2020-6-1-1-8$

Saкоvska, O. (2020). Agricultural cooperation: experience of foreign countries for Ukraine. Baltic Journal of Economic Studies, vol. 6, no. 1, pp. 118-124. doi: 10.30525/2256-0742/2020-6-1-118-124

Kritzer, B. E. (1996). Privatizing social security: the Chilean experience. Social Security Bulletin, no. 3, pp. 45-55.

Kubicek (2005). Contribution rates to funded pension systems in the new member countries. Research in International Business and Finance, vol. 19, issue 2, pp. 266-280.

Bettendorf, Leon J.H. \& Heijdra, Ben J. (2005). Population ageing and pension reform in a small open economy with non-traded goods. Journal of Economic Dynamics Control, no. 6, pp. 265-290.

Nicoholas George (2002). Sweden's savers are kept pasted on state of their funds. Financial Times. 2002. March 25, p. 7.

Todosiychuk, V. (2019). Public administration of anti-inflation policy in the system of monetary regulation of economy. Znanstvena misel journal. The journal is registered and published in Slovenia, vol. 2, no. 34, pp. 44-52.

Todosiychuk, V., \& Fedoryshyna, L. (2019). Analiz controlling financial risks of enterprise. Polish journal of science, no. 21, vol. 2, pp. 30-42.

Aleskerova, Y. (2015). Rozvytok silskohospodarskoho strakhuvannia: teoriia, metodolohiia, praktyka [Development of agricultural insurance: theory, methodology, practice]. Vinnytsia: Drukarnia Dilo. 